\title{
Skala Kesadaran Gender Untuk Siswa Sekolah Dasar (SKG-SD)
}

\author{
Guruh Sukma Hanggara', Laelatul Arofah ${ }^{2}$, Santy Andrianie ${ }^{3}$ \\ kangguruh@gmail.com ${ }^{1}$, laelatularofah@unpkediri.ac.id ${ }^{2}$, \\ santyandrianie@unpkediri.ac.id ${ }^{3}$ \\ Universitas Nusantara PGRI Kediri ${ }^{1,2,3}$
}

\begin{abstract}
Abstrak
Kesadaran gender merupakan kompetensi penting dalam perkembangan siswa SD sebagaimana terumuskan dalam SKKPD. Kasus kurangnya kesadaran gender dapat ditemukan di SD Negeri Kolomayan 2 Blitar yang belum dapat dipetakan tingkat kesadaran gendernya. Untuk dapat dijadikan sebagai landasan pemetaan maka penelitian ini bertujuan untuk menghasilkan Skala Kesadaran Gender (SKG-SD) Untuk Siswa Sekolah Dasar yang valid secara konten dan konstruk. Untuk mencapai tujuan penelitian yang diinginkan, peneliti menggunakan rancangan pengembangan instrumen. Adapun hasil yang didapatkan adalah SKG-SD dengan nilai validitas isi sebesar 1,00 yang berarti sangat layak. Selanjutnya hasil analisi butir alpha croncbach berhasil menyaring itemitem SKG-SD menjadi 16 item saja dengan nilai reliabilitas akhir sebesar 0,879 dalam kategori sangat baik dan andal.
\end{abstract}

Kata Kunci : instrumen, skala kesadaran gender, siswa SD

\begin{abstract}
Gender awareness is an important competency in the development of elementary students as formulated in the SKKPD. A case of lack of gender awareness can be found in SD Negeri 1 Kolomayan 2 Blitar, where the level of gender awareness cannot be mapped. To be used as a mapping basis, this study aims to produce a Gender Awareness Scale $(S K G-S D)$ for elementary school students that are valid in terms of content and construct. To achieve the desired research objectives, researchers used an instrument development design. The results obtained are SKG-PD with a content validity value of 1.00 , which means very feasible. Furthermore, Cronbach's alpha items' analysis succeeded in filtering the $S K G-S D$ items into only 16 items with a final reliability value of 0.879 in a very good and reliable category.
\end{abstract}

Key Word: instruments, gender awareness scale, elementary school students

Peer reviewed under responsibility of Universitas Nusantara PGRI Kediri.

(C) 2020 Guruh Sukma Hanggara, Laelatul Arofah, Santy Andrianie This is an open access article

under the CC BY-SA license ( https://creativecommons.org/licenses/by-sa/4.0/ ) 
Jurnal PINUS: Jurnal Penelitian Inovasi Pembelajaran, 6 (1), 2020, Guruh Sukma Hanggara, Laelatul Arofah, Santy Andrianie

\section{PENDAHULUAN}

Gender merupakan isu yang penting dalam berbagai bidang kehidupan khususnya keluarga, sekolah dan masyarakat. Dalam bidang Bimbingan dan Konseling di Sekolah Dasar, kajian gender merupakan salah satu aspek perkembangan siswa yang penting. Hal tersebut dirumuskan dalam Standard Kompetensi Kemandirian Peserta Didik (SKKPD), yaitu pada tugas perkembangan belajar menjalani peran sosial sesuai dengan jenis kelamin (Kemendikbud, 2016). Gender mengacu pada dimensi sosial sebagai laki-laki dan perempuan (Santrock, 2003). Dimensi sosial tersebut dapat berupa karakteristik maskulin dan feminin. Senada dengan hal tersebut (Arofah, 2016) juga mengungkapkan bahwa gender adalah konstruksi sosial-kultural yang membedakan karakteristik feminin dan maskulin merujuk pada perbedaanperbedaan dan relasi-relasi sosial antara anak perempuan dan anak laki-laki yang didasarkan pada kayakinan tertentu. Karena gender berkaitan dengan peran seseorang pada kehidupan sosial maka gender memiliki potensi untuk memberikan kontribusi sosial dan juga menimbulkan masalah. Seringkali yang menimbulkan masalah berkaitan dengan penggunakan gender untuk memaknai jenis kelamin. Sebelum lebih jauh membahas tentang gender perlu diingat bahwa gender berbeda dengan jenis kelamin (seks). Seperti yang diungkapkan (Fakih, 1996) bahwa untuk memahami konsep gender harus dibedakan kata gender dengan kata seks (jenis kelamin). Menurut (Baron, Robert
A.; Byrne, 2003) jenis kelamin (sex) didefinisikan sebagai istilah biologis berdasarkan perbedaan anatomi dan fisik antara laki-laki dan perempuan. (Henslin, 2007) memberikan pengertian tentang gender yaitu suatu ciri sosial, bukan biologis. Gender terdiri atas perilaku dan sikap apapun yang dianggap pantas bagi kaum laki-laki dan perempuan oleh suatu kelompok. Dapat disimpulkan bahwa jenis kelamin merujuk pada laki-laki dan perempuan, gender merujuk pada maskulinitas dan feminitas.

Masalah-masalah terkait dengan berbagai perbedaan akses pada dunia Pendidikan masih menjadi sorotan dalam isu gender, karena itu bertentangan dengan konsep Education for All (EFA) yang mengakui kesetaraan gender sebagai elemen penting dalam Pendidikan (UNESCO, 2003). Dalam beberapa review, bidang Pendidikan menjadi sorotan dalam masalah gender. Bahkan (Suryadi \& Idris, 2010) mengungkapkan bahwa di negara-negara berkembang kesenjangan gender pada dunia pendidikan dinilai lebih buruk. Meskipun menjadi elemen penting dalam Pendidikan, upaya untuk menyetarakan gender dalam bidang tersebut dinilai lambat (Lahelma, 2011). Tidak hanya dibidang Pendidikan, masalah gender juga disoroti dalam bidang lainnya. Pada bidang Kesehatan, gender pada dokter berpengaruh pada kesetaraan dalam kesehatan guna mewujudkan tingkat Kesehatan yang lebih baik bagi pria maupun wanita (Verdonk et al., 2008). Disamping itu gender juga dianggap memiliki peran penting dalam menentukan parameter pertumbuhan ekonomi makro (Elson, 1995). Tidak 


\section{Jurnal PINUS: Jurnal Penelitian Inovasi Pembelajaran, 6 (1), 2020, Guruh Sukma Hanggara, Laelatul Arofah, Santy Andrianie}

hanya itu, penelitian (Kinnaird \& Hall, 1996) juga menyimpulkan bahwa analisis pada aktivitas pariwisata dapat ditingkatkan dengan berfokus pada dinamika yang berhubungan dengan gender. Dari beberapa kajian tersebut dapat diketahui bahwa gender memiliki banyak pengaruh dalam berbagai bidang kehidupan.

Megingat begitu luas cakupan tentang gender, konsep tentang kesadaran gender tidaklah hanya dikembangkan dalam dunia Pendidikan semata. Isu-isu tentang gender juga harus diedukasikan pada lingkup sosial lainnya. Hal senada diungkapkan oleh (Unterhalter, 2005), bahwa kesetaraan gender sebagai salah satu unsur penting dalam terwujudnya mutu pendidikan yang baik hendaknya juga diimplementasikan dalam kehidupan masyarakat yang lebih luas, yang memungkinkan terjadinya dialogis tradisi dalam masyarakat sehingga isu ini juga nantinya menjadi kekuatan sosial tersendiri dalam kehidupan masyarakat. Dengan demikian isu gender merupakan hal penting yang diharapkan menjadi elemen yang ikut membangun perkembangan kehidupan masyarakat yang memiliki budaya luhur. Dalam mencanangkan pentingnya pendidikan gender dalam kehidupan sehari-hari, isu tentang kesadaran gender merupakan hal yang tidak terpisahkan.

Kesadaran gender merupakan komponen yang sifatnya integral dalam Pendidikan gender itu sendiri. Pemahaman akan gender merupakan hakikat dari kesadaran gender itu sendiri, sebaliknya dengan kesadaran gender yang dimiliki seseorang maka akan mudah untuk menerima isu-isu tentang gender dengan lebih mudah. Dengan adanya kesadaran gender maka setiap anak laki-laki atau perempuan diharapkan dapat mengambil peran sosial masingmasing sesuai yang berlaku dilingkungan sosio budayanya. Peran-peran tersebut dapat ditemui dan pelajari dalam beberapa lingkungan antara lain agama, keluarga, sekolah, dan masyarakat yang biasa dikenal dengan istilah peran gender. Dengan mengambil peran yang tepat, maka anak tersebut akan memiliki identitas gender yang jelas. Identitas gender menurut (Matsumoto \& Juang, 2013) mengacu pada tingkat dimana seseorang memiliki kesadaran atau pengakuan bahwa ia mengadopsi peran gender tertentu. Maka untuk memperjelas identitas gender seseorang, hal yang perlu ditingkatkan adalah kesadaran gender. Kesadaran gender merupakan pemahaman akan perbedaan peran dan hubungan antara perempuan dan lakilaki.

Pembagian peran antara laki-laki dan perempuan bukan sesuatu yang rigid atau kaku. Seperti yang diungkapkan oleh (Stromquist, 2007) gender dikonstruksi secara sosial, ia juga dapat diubah secara sosial. (Megawangi, 1999) menjelaskan bahwa diferensiasi peran antara laki-laki dan perempuan ditujukan agar ada mekanisme untuk saling melengkapi, sehingga tercipta hubungan kesatuan yang harmonis. Dengan demikian kesadaran gender merupakan keterampilan yang hendaknya dikembangkan agar dapat mencapai keharmonisan hidup yang ditandai dengan adanya saling menghormati, kerjasama dan melengkapi antara feminim dan maskulin. Agar seorang 


\section{Jurnal PINUS: Jurnal Penelitian Inovasi Pembelajaran, 6 (1), 2020, Guruh Sukma Hanggara, Laelatul Arofah, Santy Andrianie}

memiliki kesadaran gender maka sejak masih anak- anak haruslah diberi pemahaman akan identitas gender mereka.

Sayangnya hal tersebut belum dilakukan secara optimal dalam Pendidikan di SD Negeri Kolomayan 2 Blitar. Padahal menurut (Santrock, 2003) masa anak-anak merupakan masa untuk pemahaman diri (self-understanding). Dengan kata lain masa Sekolah Dasar yang menjadi basis dari masa anak-anak itu merupakan waktu yang strategis untuk memberikan pemahaman akan peran sosial mereka dalam berbagai kehidupan. Dari penggalian data awal diketahui bahwa belum ada agenda khusus untuk memberikan Pendidikan tentang kesadaran gender di SD Negeri Kolomayan 2 Blitar. Para guru belum dapat mengetahui keadaan atau pemahaman mereka terkait peran gender siswa dalam berbagai kehidupan. Dengan belum diketahui kadar pemahaman siswa terkait gender maka para guru masih kesulitan untuk memetakan baseline kesadaran gender mereka. Jika keadaan kesadaran gender siswa belum dapat diukur maka guru dan pihak sekolah juga kesulitan dalam menentukan strategi dan metode yang harus digunakan untuk meningkatkan kesadaran gender.

Diperlukan suatu instrumen khusus untuk dapat mengetahui tingkat kesadaran gender siswa SD, sehingga pengembangan kesadaran siswa SD dapat diketahui keberhasilanya secara lebih objektif dan terukur. Dari hasil review beberapa instrument terkait gender, peneliti belum menemukan instrumen yang spesifik untuk mengukur kesadaran gender pada siswa SD. Beberapa instrument yang dimaksud antara lain adalah: (1) Gender Awareness InventoryVA (Salgado et al., 2002) yang diperuntukkan mengukur ideologi, sensitifitas dan pengetahuan yang berhubungan dengan kesehatan wanita veteran, (2) The Nijmegen Gender Awareness in Medicine Scale (N-GAMS) (Morais et al., 2020) yang digunakan untuk mengukur kesadaran gender mahasiswa bidang medis, (3) (FGRS) Feminine Gender Role Stress (Good et al., 2000) yang mengukur tingkat stres seseorang akibat kegagalan dalam menjalankan peran gender tradisional. Beberapa instrumen tersebut merupakan instrumen yang digunakan untuk mengukur kesadaran gender seseorang, akan tetapi yang spesifik untuk mengukur kesadaran gender pada anak-anak atau anak SD belum dikembangkan.

Secara operasional, kesadaran gender siswa SD dapat dipahami sebagai pemahaman terhadap peran sosial yang melekat pada siswa sekolah dasar baik laki-laki dan perempuan dalam lingkungan keagamaan, keluarga, sekolah maupun masyarakat. Kesadaran gender yang hendak diukur merupakan typical performansi seseorang yang kesimpulanya dapat menggambarkan kecenderungan seseorang pada tingkat pemahaman siswa pada peran gendernya. Menurut (Azwar, 2011) performansi tipikal ini cocok jika diukur dengan instrument yang berbentuk skala. Penelitian ini merupakan tahap awal sebelum menginjak pada pengembangan media BK berbasis video animasi yang dikembangkan oleh peneliti. Sesuai dengan rangkaian tahapan penelitian, salah satu hal yang harus dilakukan oleh 


\section{Jurnal PINUS: Jurnal Penelitian Inovasi Pembelajaran, 6 (1), 2020, Guruh Sukma Hanggara, Laelatul Arofah, Santy Andrianie}

peneliti yaitu mengembangkan sebuah instrumen. Instrumen yang dimaksud yaitu Skala Kesadaran Gender Siswa SD. Berdasarkan kajian konsep dan fenomena lapangan yang didapat, maka penelitian ini bertujuan untuk menghasilkan Skala Kesadaran Gender Untuk Siswa Sekolah Dasar (SKG-SD) yang valid secara konten dan konstruk.

\section{METODE}

Untuk mencapai tujuan penelitian yang diinginkan, peneliti menggunakan rancangan pengembangan, yang akan menghasilkan instrumen pemahaman individu berupa Skala Kesadaran Gender Untuk Siswa Sekolah Dasar (SKG-SD). Dalam mengembangkan skala tersebut, peneliti merujuk Langkah yang disarankan oleh (Gregory, 2015) yang meliputi; (1) mendefinisikan tes; (2) menyeleksi metode penskalaan; (3) Mengkonstruk item; (4) Menguji Item, dalam menguji item ini peneliti berusaha mengujikanya baik secara konten yaitu dengan Expert judgment Ahli maupun secara konstruk yaitu dengan analisis butir; (5) Merevisi; dan Mempublikasikannya.

Sebagai subyek penelitian, pada penelitian ini melibatkan ahli asesmen BK yang berlatar belakang Pendidikan linier pada bidang bimbingan dan konseling yang aktif sebagai dosen pengajar program studi BK, serta ahli dari Pendidikan sekolah dasar yang aktif sebagai pengajar program studi Pendidikan Guru Sekolah Dasar (PGSD) dalam memberikan penilaian Expert judgment. Selain itu, penelitian ini juga diujicobakan pada subyek penelitian yaitu siswa SD Negeri Kolomayan 2
Blitar, tempat dimana fenomena lapangan ditemukan. Dalam uji coba instrument dipilih siswa kelas tinggi yaitu kelas VI yang dianggap telah memiliki pengalaman paling lengkap selama menjadi siswa SD, disamping juga dari sisi kemampuan memahami Bahasa memiliki tingkat perkembangan yang lebih tinggi pula.

Dalam pengumpulan data, peneliti mengkategorikan menjadi dua yaitu data berupa Expert judgment Ahli dan data hasil uji coba pada subjek penelitian. Dalam memperoleh data Expert judgment Ahli, peneliti menempuh Langkah antara lain: (1) Mempelajari ahli yang kompeten dan menghubunginya; (2) Menyerahkan draft SKG-SD dan juga lembar penilaian dan saran untuk mendapatkan data yang diinginkan; (3) Mengambil hasil penilaian Ahli yang disertai dengan diskusi dengan ahli tersebut; (4) Melakukan analisis terhadap data Expert judgment Ahli yang diperoleh; dan (5) Melakukan revisi instrumen sesuai masukan ahli dan hasil uji validitas konten yang dilakukan. Sedangkan untuk mendapatkan data kuantitatif sebagai bahan uji validitas konstruk, peneliti menempuh langkah antara lain: (1) Menetapkan subjek penelitian dengan Teknik purposive sampling yang didasarkan pada fenomena penelitian ditemukan, kekomprehensifan pengalaman belajar, dan kemampuan Bahasa subyek penelitian yang diharapkan mampu memahami maksud Bahasa pada masing-masing item skala, (2) Melakukan pengambilan data pada subyek penelitan terpilih; (3) Melakukan analisis data; serta (4) Melakukan revisi terhadap blue-print sesuai hasil analisis 
Jurnal PINUS: Jurnal Penelitian Inovasi Pembelajaran, 6 (1), 2020, Guruh Sukma Hanggara, Laelatul Arofah, Santy Andrianie

butir; lalu (5) merakit SKG-SD yang baru sesuai dengan blue-print yang baru.

Penelitian ini menggunakan dua analisis untuk mencapai tujuan penelitian yang diharapkan. Analisis yang pertama adalah menghitung validitas kontennya. Validitas konten dapat dihitung dengan rumus sebagai berikut:
Content Validity $=\frac{D}{(A+B+C+D)}$

Sumber: (Gregory, 2015)

Dimana A, B, C, D merupakan jumlah item yang berasal dari dalam kolom model intereter agreement berikut:

\section{Expert judge Ahli Pertama}

Relevansi Lemah Relevansi Kuat (penilaian item 1-2) (penilaian item 3-

4)

\begin{tabular}{|ll|l|l|}
\cline { 3 - 3 } $\begin{array}{l}\text { Expert } \\
\text { judge Ahli }\end{array}$ & $\begin{array}{l}\text { Relevansi Lemah } \\
\text { (penilaian item 1-2) } \\
\text { Kedua }\end{array}$ & A & B \\
\cline { 3 - 4 } & $\begin{array}{l}\text { Relevansi Kuat } \\
\text { (penilaian item 3-4) }\end{array}$ & C & D \\
\hline
\end{tabular}

Gambar.1 intereter agreement (Gregory, 2015)

Setelah dilakukan penghitungan seperti yang ditunjukan model diatas maka hasilnya akan diketahui masuk kriteria yang mana dalam menentukan validitas kontennya. Adapun kategori validitas yang dimaksud ditentukan dengan membuat kelas interval dengan tiga kelas interval, jika nilai validitas kontennya berada pada kisaran (0-0,33) maka instrument tersebut dianggap tidak layak, sedangkan pada kisaran $(0,34-0,66)$ dianggap cukup layak dan jika pada kisaran (0,67-1) dianggap sangat layak. Sedangkan analisis yang kedua adalah untuk mengetahui validitas konstruknya berikut reliabilitasnya yang keduanya dilakukan dengan analisis butir alpha croncbach dengan bantuan softwere SPSS Versi 25. Adapun ketentuan validitas konstruknya, jika nilai corrected butir-total correlation $\geq 0,3$ maka item tersebut dinilai valid, sedangkan item dengan nilai corrected butir-total correlation $<0,3$ maka item tersebut dinilai tidak valid sehingga dibuang dan tidak diikutkan pada analisis berikutnya. Demikian dilakukan analisis butir dengan menggunakan SPSS dilakukan berulang sampai tidak lagi ditemukan item dengan nilai corrected butir-total correlation < 0,3 .

\section{HASIL}

Pada pengembangan SKG-SD ini, sebagaimana yang direkomendasikan (Gregory, 2015), maka diawali dengan mendefinisikan tes. Hal ini dilakukan dengan pengkajian teori sesuai fenomena yang ditemukan kemudian didefinisikan secara operasional. Berdasarkan definisi tersebut kemudian diekstraksi sehingga dihasilkan 2 indikator, 8 deskriptor dan 34 item pernyataan. Selanjutnya ditentukan menggunakan instrumen dengan model skala mengingat informasi 
Jurnal PINUS: Jurnal Penelitian Inovasi Pembelajaran, 6 (1), 2020, Guruh Sukma Hanggara, Laelatul Arofah, Santy Andrianie

yang ingin diperoleh adalah performansi tipikal dari siswa SD. SKG-SD memiliki empat pilihan penskalaan yaitu (SS) Sangat Setuju, (S) Setuju, (TS) Tidak Setuju dan (STS) Sangat Tidak Setuju, dengan rentang nilai pentabulasian 1-4 tergantung bentuk pernyataan yang dibuat baik favorable maupun unfavorable yang tentunya memiliki ketentuan skoring yang berkebalikan.

\section{SKG-SD Pasca Uji Ahli}

Setelah dilakukan uji ahli guna mengetahui validitas isi dari skala ini diperoleh akumulasi data sebagai berikut:

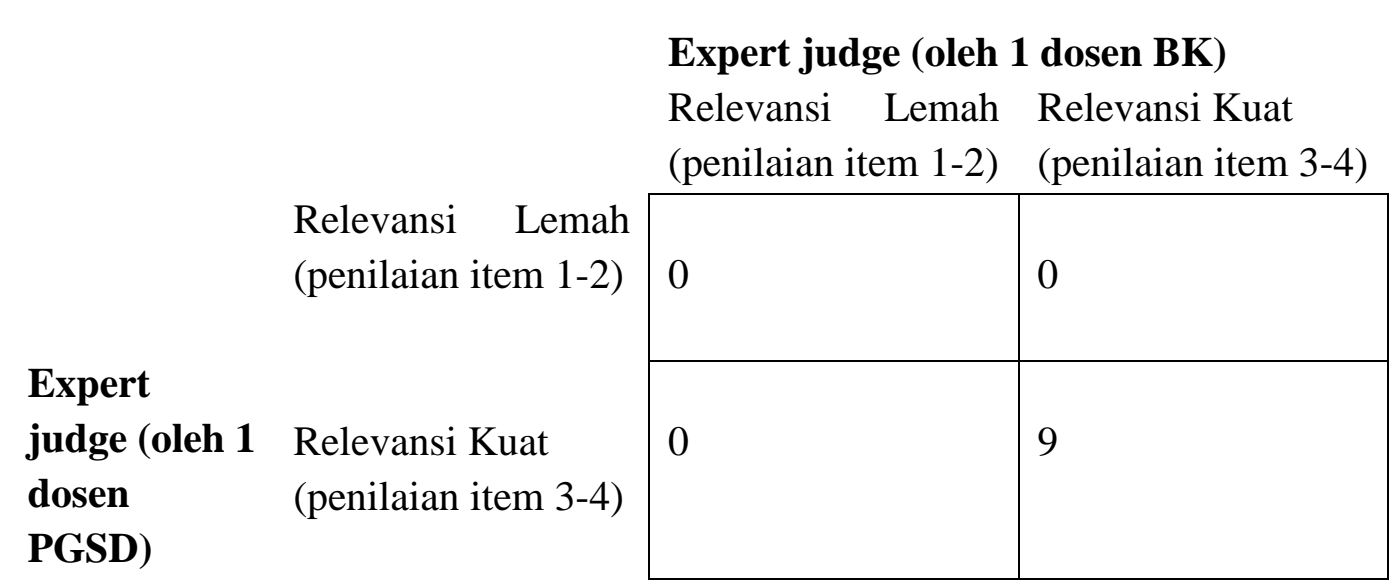

Gambar.2 Penghitungan intereter agreement

Berdasarkan akumulasi sebagaimana pada tabel. 2 maka jika dimasukan dalam rumus mencari nilai validitas konten yaitu sebagai berikut:

$$
\text { Content Validity }=\frac{9}{(0+0+0+9)}
$$

Dengan demikian diketahui bahwa nilai dari validitas konten yaitu 1,00 yang berarti bahwa SKG-SD memiliki kriteria kelayakan yang tergolong sangat layak. Meskipun demikian ada beberapa masukan ahli yang bersifat kualitatif karena berupa masukan dan saran. Namun Semua item yang diujikan dinilai layak untuk digunakan, sehingga hal tersebut tidak mengurangi jumlah item pada skala ini. Kesimpulan dari penilaian ahli I menerangkan bahwa instrumen dapat langsung digunakan akan tetapi ahli II merekomendasikan bahwa instrumen dapat digunakan dengan revisi. Saran dan masukan para ahli dapat dirangkum sebagai berikut:

\section{Tabel. 1 Saran \& Masukan Ahli}

\begin{tabular}{lll}
\hline No & Saran/ Masukan & Tindakan Peneliti \\
\hline 1 & Mungkin perlu diberikan keterangan & Sebagai acuan guru, pada \\
& pembeda antara kalimat positif dan negatif & instrument yang menjadi \\
& pada lembar skala kesadaran gender (pada & pegangan guru diberikan \\
& lembar yang bukan untuk responden) agar & pembeda antara kalimat positif \\
\hline
\end{tabular}


Jurnal PINUS: Jurnal Penelitian Inovasi Pembelajaran, 6 (1), 2020, Guruh Sukma Hanggara, Laelatul Arofah, Santy Andrianie

\begin{tabular}{|c|c|c|}
\hline & $\begin{array}{l}\text { terlihat jelas antara pernyataan positif dan } \\
\text { negatif. (Ahli I) }\end{array}$ & $\begin{array}{l}\text { dan negatif berikut norma } \\
\text { penskorannya }\end{array}$ \\
\hline 2 & $\begin{array}{l}\text { Penggunaan istilah dalam aitem } \\
\text { pernyataan dapat disesuaikan kembali } \\
\text { dengan jenjang subjek agar memudahkan } \\
\text { dalam mengisi dan menghilangkan } \\
\text { ambiguitas. (Ahli II) }\end{array}$ & $\begin{array}{l}\text { Mengkaji kembali kalimat- } \\
\text { perkalimat agar level Bahasa } \\
\text { yang digunakan sesuai dengan } \\
\text { kemampuan Bahasa siswa SD }\end{array}$ \\
\hline 3 & $\begin{array}{l}\text { Item nomor 1-4 perlu diperjelas bedanya, } \\
\text { karena jika maksudnya sama jawaban } \\
\text { yang diberikan akan relatif sama (Ahli II) }\end{array}$ & Memperjelas kalimat \\
\hline 4 & $\begin{array}{l}\text { Item nomor } 14 \text { dan } 20 \text { kurang operasional } \\
\text { (Ahli II) }\end{array}$ & $\begin{array}{l}\text { Mengoperasionalkan kalimat } \\
\text { pada item nomor } 14 \text { dan } 20\end{array}$ \\
\hline 5 & $\begin{array}{l}\text { Item nomor } 19 \text { masih menggunakan istilah } \\
\text { Bahasa inggris (Ahli II) }\end{array}$ & $\begin{array}{l}\text { Mengganti istilah Bahasa inggris } \\
\text { dengan kata yang mudah } \\
\text { dipahami }\end{array}$ \\
\hline 6 & $\begin{array}{l}\text { Item nomor } 29 \text { lebih operasional jika } \\
\text { langsung dirangkai dengan contoh (Ahli } \\
\text { II) }\end{array}$ & $\begin{array}{l}\text { Mengganti kata "Tegas" yang } \\
\text { dimaksudkan ahli, dengan } \\
\text { kalimat yang lebih operasional }\end{array}$ \\
\hline 7 & $\begin{array}{l}\text { Item nomor } 29 \text { sebaiknya kalimat "karena } \\
\text { menangis adalah perilaku yang wajar" di } \\
\text { hapus dari rangkaian pernyataan item } \\
\text { (Ahli II) }\end{array}$ & $\begin{array}{l}\text { Menghapus prase kalimat yang } \\
\text { dimaksudkan ahli }\end{array}$ \\
\hline
\end{tabular}

Berdasarkan evaluasi para ahli terhadap SKG-SD, semua item dapat digunakan untuk mengukur keadaan kesadaran gender siswa SD. Akan tetapi peneliti melakukan pembenahan dan revisi terutama pada struktur kalimat sebagaimana saran para ahli. Dengan demikian intrumen dapat diuji-cobakan pada siswa SD untuk selanjutnya mendapatkan data untuk melakukan validitas konstruk.

\section{SKG-SD Pasca Analisis Butir Alpha Croncbach}

Setelah dilakukan uji ahli dan revisi kemudian SKG-SD dilancarkan pada subyek penelitan yaitu siswa kelas VI, SD Negeri Kolomayan 2 Blitar yang berjumlah 30 siswa. Berdasarkan jawaban dari para siswa kemudian ditabulasi, dilakukan screening dan kemudian dianalsis dengan metode analysis butir alpha croncbach. Hasil analisis pertama menunjukan bahwa nilai reliabilitas SKG-SD sebesar 0,711 dan item-item yang tidak valid antara lain yaitu item nomor: $2,4,5,6,7,8,9,10,12,13,16$, 
Jurnal PINUS: Jurnal Penelitian Inovasi Pembelajaran, 6 (1), 2020, Guruh Sukma Hanggara, Laelatul Arofah, Santy Andrianie

$17,20,25,26,28,30$ dan 33 yang tidak

Tabel 2 Reliabilitas Awa diikutkan dalam analisis selanjutnya. Secara lebih rinci dapat diamati pada tabel berikut :

\section{Reliability Statistics}

Cronbach's

\begin{tabular}{ll} 
Alpha & N of Items \\
\hline .711 & 34 \\
\hline
\end{tabular}

Tabel 3. Analisis Butir Awal

\begin{tabular}{|c|c|c|c|c|c|}
\hline \multicolumn{6}{|c|}{ Item-Total Statistics } \\
\hline & Scale & Scale & & Cronbach's & \multirow{4}{*}{ KETERANGAN } \\
\hline & Mean if & Variance if & Corrected & Alpha if & \\
\hline & Item & Item & Item-Total & Item & \\
\hline & Deleted & Deleted & Correlation & Deleted & \\
\hline Item 1 & 99,38 & 79,530 & 0,448 & 0,696 & Valid \\
\hline Item 2 & 99,21 & 86,241 & $-0,230$ & 0,721 & Tidak Valid \\
\hline Item3 & 99,17 & 80,076 & 0,446 & 0,697 & Valid \\
\hline Item4 & 99,21 & 80,884 & 0,201 & 0,705 & Tidak Valid \\
\hline Item5 & 99,24 & 85,190 & $-0,100$ & 0,724 & Tidak Valid \\
\hline Item6 & 99,93 & 79,852 & 0,136 & 0,713 & Tidak Valid \\
\hline Item7 & 99,41 & 87,394 & $-0,280$ & 0,728 & Tidak Valid \\
\hline Item8 & 101,21 & 97,313 & $-0,837$ & 0,761 & Tidak Valid \\
\hline Item9 & 99,62 & 79,101 & 0,189 & 0,707 & Tidak Valid \\
\hline Item 10 & 99,76 & 76,690 & 0,286 & 0,699 & Tidak Valid \\
\hline Item11 & 99,10 & 74,596 & 0,645 & 0,679 & Valid \\
\hline Item12 & 101,48 & 86,759 & $-0,311$ & 0,723 & Tidak Valid \\
\hline Item13 & 101,41 & 85,537 & $-0,148$ & 0,719 & Tidak Valid \\
\hline Item14 & 99,24 & 78,975 & 0,440 & 0,695 & Valid \\
\hline Item15 & 99,21 & 72,527 & 0,746 & 0,670 & Valid \\
\hline Item 16 & 100,48 & 80,973 & 0,109 & 0,713 & Tidak Valid \\
\hline Item17 & 101,55 & 84,399 & $-0,047$ & 0,719 & Tidak Valid \\
\hline Item18 & 99,03 & 78,820 & 0,559 & 0,692 & Valid \\
\hline Item19 & 99,69 & 74,793 & 0,357 & 0,693 & Valid \\
\hline Item20 & 99,48 & 76,830 & 0,291 & 0,699 & Tidak Valid \\
\hline Item21 & 99,24 & 70,761 & 0,874 & 0,661 & Valid \\
\hline Item 22 & 99,10 & 78,810 & 0,532 & 0,693 & Valid \\
\hline Item 23 & 99,00 & 77,071 & 0,684 & 0,685 & Valid \\
\hline Item24 & 99,00 & 80,357 & 0,485 & 0,698 & Valid \\
\hline Item 25 & 99,41 & 81,323 & 0,271 & 0,703 & Tidak Valid \\
\hline
\end{tabular}


Jurnal PINUS: Jurnal Penelitian Inovasi Pembelajaran, 6 (1), 2020, Guruh Sukma Hanggara, Laelatul Arofah, Santy Andrianie

\begin{tabular}{llllll}
\hline Item26 & 101,03 & 83,177 & 0,043 & 0,714 & Tidak Valid \\
\hline Item27 & 99,28 & 75,921 & 0,504 & 0,686 & Valid \\
\hline Item28 & 99,38 & 80,744 & 0,160 & 0,708 & Tidak Valid \\
\hline Item29 & 99,41 & 71,751 & 0,705 & 0,669 & Valid \\
\hline Item30 & 100,17 & 77,576 & 0,239 & 0,704 & Tidak Valid \\
\hline Item31 & 99,45 & 76,399 & 0,362 & 0,693 & Valid \\
\hline Item32 & 99,79 & 69,313 & 0,603 & 0,668 & Valid \\
\hline Item33 & 101,03 & 95,034 & $-0,522$ & 0,763 & Tidak Valid \\
\hline Item34 & 98,90 & 80,096 & 0,655 & 0,696 & Valid \\
\hline
\end{tabular}

Dengan menghilangkan item yang tidak valid pada analisis pertama, melalui analisis butir yang kedua ini diperoleh bahwa nilai reliabilitas SKG-SD meningkat menjadi 0,879 . Sedangkan hasil analisis butir pada tahap kedua ini tidak lagi ditemukan item dengan nilai Corrected Item-Total Correlation < 0,3. Dengan kata lain 16 item yang dianalisis pada tahap ini semuanya valid. Secara lebih jelas dapat diamati pada tabel dibawah ini:

Tabel 4. Reliabilitas Akhir

Reliability Statistics

Cronbach's

Alpha $\quad \mathrm{N}$ of Items

\begin{tabular}{rr}
.879 & 16 \\
\hline
\end{tabular}

Tabel 5. Analisis Butir Akhir

\begin{tabular}{|c|c|c|c|c|c|}
\hline \multicolumn{6}{|c|}{ Item-Total Statistics } \\
\hline & Scale & Scale & & Cronbach's & \multirow{4}{*}{ KETERANGAN } \\
\hline & Mean & Variance & Corrected & Alpha if & \\
\hline & if Item & if Item & Item-Total & Item & \\
\hline & Deleted & Deleted & Correlation & Deleted & \\
\hline Item1 & 52,90 & 57,128 & 0,323 & 0,879 & Valid \\
\hline Item3 & 52,63 & 56,447 & 0,503 & 0,874 & Valid \\
\hline Item11 & 52,57 & 52,254 & 0,652 & 0,867 & Valid \\
\hline Item14 & 52,70 & 55,872 & 0,446 & 0,875 & Valid \\
\hline Item15 & 52,67 & 50,092 & 0,793 & 0,860 & Valid \\
\hline Item18 & 52,50 & 55,293 & 0,632 & 0,871 & Valid \\
\hline Item19 & 53,13 & 53,016 & 0,316 & 0,889 & Valid \\
\hline Item21 & 52,70 & 48,907 & 0,899 & 0,855 & Valid \\
\hline Item22 & 52,57 & 55,564 & 0,564 & 0,872 & Valid \\
\hline Item23 & 52,47 & 54,257 & 0,702 & 0,868 & Valid \\
\hline
\end{tabular}


Jurnal PINUS: Jurnal Penelitian Inovasi Pembelajaran, 6 (1), 2020, Guruh Sukma Hanggara, Laelatul Arofah, Santy Andrianie

\begin{tabular}{llllll}
\hline Item24 & 52,47 & 57,292 & 0,458 & 0,876 & Valid \\
\hline Item27 & 52,73 & 53,168 & 0,522 & 0,872 & Valid \\
\hline Item29 & 52,87 & 49,844 & 0,711 & 0,863 & Valid \\
\hline Item31 & 53,00 & 53,310 & 0,354 & 0,884 & Valid \\
\hline Item32 & 53,23 & 47,771 & 0,604 & 0,872 & Valid \\
\hline Item34 & 52,37 & 56,861 & 0,667 & 0,873 & Valid \\
\hline
\end{tabular}

Dengan demikian analisis butir yang dilakukan dapat dikatakan selesai. Langkah selanjutnya yaitu merevisi blueprint dengan menghapus item-item yang dianggap tidak valid. Selanjutnya berdasarkan blue-print, peneliti kemudian mengemasnya dalam SKG-SD yang baru yang terdiri dari 16 item yang valid.

\section{PEMBAHASAN}

Dari serangkaian uji coba dan evaluasi terhadap kelayakan SKG-SD, didapatkan Skala Kesadaran Gender Untuk Siswa Sekolah Dasar (SKG-SD) yang valid secara konten dan konstruk. Adapaun SKG-SD yang dihasilkan memiliki 16 butir item yang valid dan reliabel. Dari 16 butir tersebut dirasa cukup untuk dapat mengungkap tentang kesadaran gender siswa SD. Dari sisi validitas konten masing-masing indikator yang ditetapkan telah terwakili oleh item yang diperoleh. Dari sisi validitas konstruk, item-item yang terpilih telah memiliki korelasi yang baik. Dan berdasarkan perhitungan reliabilitas memiliki nilai kehandalan yang ideal.

Secara Konten, koefisien validitas sebesar 1,00 merupakan skor yang utuh dari hasil penilaian para ahli. Validitas konten merupakan salah satu hal yang esensial untuk dilakukan dalam pengembangan instrumen psikometri (Zamanzadeh et al., 2015). Langkah ini telah dilakukan dan diambil tindak lanjut oleh peneliti. Meskipun tidak ada penghapusan item pada tahap ini, peneliti tetap melakukan revisi sesuai rekomendasi para ahli. Dari evaluasi para ahli dapat diketahui bahwa lebih menekankan pada perbaikan struktur kalimat. Sedangkan kesesuaian antara topik dan item yang dihasilkan dari blueprint intrumen tidak ditemukan masalah. Dengan demikian proses evaluasi ahli ini, SKG-SD secara konten layak untuk digunakan.

Untuk menguji validitas konstruk dalam pengembangan instrument ini, dipilih analisis butir alpha Cronbach. Analisis ini cocok untuk mengetahui valid-tidaknya suatu item berada dalam keseluruhan item yang ada dalam instrumen tersebut. Analisis ini dilakukan dengan mengetahui korelasi setiap butir item terhadap total skor sebagaimana yang direkomendasikan oleh (Cronbach, 1990) dimana item yang nilai korelasinya $\geq 0,3$ dianggap valid. Dari analisis itu terbukti dari 34 item yang diuji, hanya 16 butir yang layak digunakan untuk pengambilan data tentang kesadaran gender. Dengan demikian meskipun 


\section{Jurnal PINUS: Jurnal Penelitian Inovasi Pembelajaran, 6 (1), 2020, Guruh Sukma Hanggara, Laelatul Arofah, Santy Andrianie}

memiliki item yang relatif sedikit, namun instrument ini telah dievaluasi secara konstruk dan layak digunakan untuk pengambilan data tentang kesadaran gender siswa Sekolah Dasar.

Hal lain yang tidak kalah penting dalam mempertimbangkan kelayakan suatu intrumen pengukuran adalah reliabilitas atau kehandalan. Dalam menentukan kehandalan SKG-SD ini digunakan penghitungan model alpha cronbach's. Dari penghitungan yang dihasilkan yaitu reliabilitas awal bernilai alpha cronbach's sebesar 0,711. Hasil tersebut sebenarnya masuk dalam kategori dapat diterima (Ursachi et al., 2015), akan tetapi menurut (Fisher, 2007) rentang itu hanya masuk dalam kategori cukup dan dari sisi validitas banyak ditemukan item yang tidak dapat digunakan karena tidak valid. Dari hasil analisis yang tidak menyertakan item yang tidak valid diperoleh reliabilitas alpha cronbach's yang lebih besar yaitu 0,879 . Nilai tersebut menurut (Ursachi et al., 2015) masuk dalam kategori sangat baik, dan menurut (Taber, 2018) masuk dalam kategori andal. Dari perhitungan reliabilitas tersebut dapat diketahui bahwa ada peningkatan level kehandalan yang diperoleh dan menjadikan SKG-SD menjadi semakin layak untuk digunakan. Hasil perhitungan akhir yang menunjukan angka 0,879 merupakan nilai yang ideal, tidak terlalu rendah dan juga tidak terlalu tinggi, karena jika terlalu tinggi misalnya sampai diatas 0,95 ada indikasi adanya redundansi (Hulin et al., 2001).

Konsep kesadaran gender yang menjadi pangkal dari pengembangan instrument ini lebih condong pada pendalaman kognitif karena menekankan pada pemahaman siswa pada peran gender maskulin dan feminism. Peran maskulin dan feminism diperkenalkan kepada siswa dalam rangka untuk memberikan pemahaman bahwa laki-laki dan perempuan memiliki kekhasan dalam perilakunya. Ada beberapa perilaku yang hanya bisa dilakukan oleh laki-laki sedangkan perempuan tidak bisa, begitupun sebaliknya. Ada juga perilaku yang dapat dipertukarkan satu sama lain, dianggap wajar dan butuh komitmen dari satu sama lain (laki-laki dan perempuan). Pemahaman tentang peran gender lakilaki dan perempuan penting untuk dipahami, salah satunya oleh siswa SD. Siswa SD dianggap masih berada pada tahap perkembangan awal dimana segala hal yang ditanamkan akan dapat diserap dan diamalkan. Melalui pengembangan SKG-SD guru SD akan terbantu untuk memetakan tingkat kesadaran gender siswanya. Dari hasil yang didapat peneliti, SKG-SD sudah memiliki reliabilitas yang tinggi yaitu 0.879 yang artinya salah satu unsur dalam pengembangan sebuah instrumen sudah terpenuhi. Selanjutnya peneliti tinggal memasukkan pesan yang ada dalam setiap indikator SKG-SD ke dalam media berupa video animasi yang saat ini tengah dikembangkan oleh peneliti. Diharapkan dengan adanya media tersebut siswa dapat mendalami dari segi kognitif tentang laki-laki dan perempuan yang sadar gender seperti apa.

Setelah pemaparan di atas, instrumen SKG-SD memiliki kelebihan yaitu sebagai salah satu instrumen yang 


\section{Jurnal PINUS: Jurnal Penelitian Inovasi Pembelajaran, 6 (1), 2020, Guruh Sukma Hanggara, Laelatul Arofah, Santy Andrianie}

dapat dijadikan oleh guru SD dalam mengukur sejauhmana tingkat kesadaran gender siswa SD. SKG-SD penting untuk dikembangkan mengingat belum ada penelitian yang mengembangkan SKGSD padahal kesadaran gender merupakan salah satu kompetensi yang harus dikuasai oleh siswa SD. Hal tersebut seperti yang dijelaskan dalam Standard Kompetensi Kemandirian Peserta Didik (SKKPD), yaitu pada tugas perkembangan belajar menjalani peran sosial sesuai dengan jenis kelamin (Kemendikbud, 2016) Bentuk kesadaran gender yang dimaksud meliputi tataran mengenal diri sebagai laki-laki atau perempuan, menerima atau menghargai diri sebagai laki-laki atau perempuan, berperilaku sesuai dengan peran sebagai laki-laki atau perempuan. SKD-SD yang sudah valid dan reliabel ini akan dijadikan sebagai landasan dalam menentukan tema video animasi kesadaran gender yang dikembangkan oleh peneliti. Dalam pengembangan SKD-SD ini tentunya tidak terlepas dari keterbatasan yang ada. Salah satu keterbatasan dalam pengembangan SKDSD ini yaitu instrumen ini hanya diperuntukkan untuk siswa SD sehingga jika nanti akan digunakan untuk jenjang yang lebih tinggi harus melalui kajian teori terlebih dahulu agar sesuai dengan sasaran penelitian. Oleh karena itu, bagi peneliti selanjutnya bisa menggunakan SKD-SD ini sebagai acuan untuk mengembangkan skala pada jenjang lebih tinggi dengan memperhatikan teori yang relevan pada jenjang yang dituju.

\section{KESIMPULAN}

Kontruksi dan Validasi Skala Kesadaran Gender untuk Siswa Sekolah Dasar (SKG-SD) menghasilkan 16 butir yang dinilai valid dan telah mewakili masing-masing indikator. Hasil validitas konten menunjukan keberterimaan yang utuh dari penghitungan expert judgment intereter para ahli, serta beberapa masukan dan saran telah direvisi. Hasil validitas konstruk melalui analisis butir membuahkan hasil 16 butir valid dengan nilai reliabilitas sebesar 0,879 yang masuk dalam kategori sangat baik dan andal.

\section{DAFTAR RUJUKAN}

Arofah, L. (2016). Penyadaran Gender Siswa MA melalui Layanan Informasi dengan Media Komik dalam Perspektif Islam. Nusantara of Research: Jurnal Hasil-Hasil Penelitian Universitas Nusantara PGRI Kediri (e-Journal), 3(1), 24-31.

Azwar, S. (2011). Reliabilitas Dan Validitas. Yogyakarta: Pustaka Pelajar.

Baron, Robert A.; Byrne, D. (2003). Psikologi Sosial Edisi Kesepuluh. Erlangga.

Cronbach, L. J. (1990). Essentials of psychological testing. Harper Collins Pubisher.

Elson, D. (1995). Gender Awareness in Modeling Structural Adjustment. World Development. https://doi.org/10.1016/0305750X(95)00087-S 
Jurnal PINUS: Jurnal Penelitian Inovasi Pembelajaran, 6 (1), 2020, Guruh Sukma Hanggara, Laelatul Arofah, Santy Andrianie

Fakih, M. (1996). Analisis gender \& transformasi sosial. Pustaka Pelajar.

Fisher, W. P. (2007). Rasch Measurement and the R Statistics Environment. Rasch Measurement Transactions, 21(1), 1087.

Good, G. E., Sherrod, M. B., \& Dillon, M. G. (2000). Masculine gender role stressors and men's health. In Handbook of gender, culture, and health (pp. 63-81). Lawrence Erlbaum Associates Publishers.

Gregory, R. J. (2015). Psychological Testing: History, Principles, and Applications, 7th Edition. Pearson Education.

Henslin, J. . (2007). Sosiologi dengan Pendekatan Membumi Edisi 6. Erlangga.

Hulin, C., Netemeyer, R. G., \& Cudeck, R. (2001). Can a Reliability Coefficient Be Too High? Journal of Consumer Psychology, 10(1), 55-58.

https://doi.org/10.2307/1480474

Kemendikbud. (2016). Panduan Operasional Penyelenggaraan Bimbingan dan Konseling Sekolah Dasar (SD). Ditjen Guru Dan Tenaga Kependidikan Kemdikbud.

Kinnaird, V., \& Hall, D. (1996). Understanding tourism processes: A gender-aware framework. Tourism Management. https://doi.org/10.1016/02615177(95)00112-3
Lahelma, E. (2011). Gender Awareness in Finnish Teacher Education: an Impossible Mission? Education Inquiry, 2(2), 263-276. https://doi.org/10.3402/edui.v2i2. 21979

Matsumoto, D., \& Juang, L. (2013). Culture \& Psychology, 5th. Wadsworth, Cengage Learning.

Megawangi, R. (1999). Membiarkan Berbeda: Sudut Pandang Baru Relasi Gender. Mizan Pustaka.

Morais, R., Bernardes, S. F., \& Verdonk, P. (2020). Gender awareness in medicine: adaptation and validation of the Nijmegen Gender Awareness in Medicine Scale to the Portuguese population (N-GAMS). Advances in Health Sciences Education. https://doi.org/10.1007/s10459019-09936-y

Salgado, D. M., Vogt, D. S., King, L. A., \& King, D. W. (2002). Gender Awareness Inventory-VA: A measure of ideology, sensitivity, and knowledge related to women veterans' health care. Sex Roles. https://doi.org/10.1023/A:102017 1416038

Santrock. (2003). Life-Span Development: Perkembangan Masa Hidup. In Erlangga. https://doi.org/10.1109/ciced.201 8.8592188

Stromquist, N. (2007). The Gender Socialization Process in Schools: A Cross-National Comparison. 
Jurnal PINUS: Jurnal Penelitian Inovasi Pembelajaran, 6 (1), 2020, Guruh Sukma Hanggara, Laelatul Arofah, Santy Andrianie

Suryadi, A., \& Idris, E. (2010). Kesetaraan Gender Dalam Bidang Pendidikan. Genessindo.

Taber, K. S. (2018). The Use of Cronbach's Alpha When Developing and Reporting Research Instruments in Science Education. Research in Science Education.

https://doi.org/10.1007/s11165016-9602-2

UNESCO. (2003). Gender and education for all: the leap to equality; EFA global monitoring report, 2003/4; summary report. UNESCO Publishing.

Unterhalter, E. (2005). Global inequality, capabilities, social justice: The millennium development goal for gender equality in education. International Journal of Educational Development, 25, 111-122.

https://doi.org/10.1016/j.ijedudev.2 004.11 .015

Ursachi, G., Horodnic, I. A., \& Zait, A. (2015). How Reliable are Measurement Scales? External
Factors with Indirect Influence on Reliability Estimators. Procedia Economics and Finance. https://doi.org/10.1016/s22125671(15)00123-9

Verdonk, P., Benschop, Y., Haes, Y. de, \& Lagro-Janssen, A. L. M. (2008). Medical students' gender awareness : construction of the Nijmegen Gender Awareness In Medicine Scale (N-GAMS). Sex Roles, 58, 222-234. https://doi.org/10.1007/s11199007-9326-x

Zamanzadeh, V., Jasemi, M., Valizadeh, L., Keogh, B., \& Taleghani, F. (2015). Effective factors in providing holistic care: a qualitative study. Indian Journal of Palliative Care, 21(2), 214224.

https://doi.org/10.4103/0973-

1075.156506 